\title{
AORTIC VALVE GRAFT IMPLANTATION IN RATS: A NEW FUNCTIONAL MODEL
}

Jean-Francois Légaré, MDa

Maurice A. Nanton, $\mathrm{MBChB}^{\mathrm{b}}$

Patricia Bryan, RDCS

Timothy D. G. Lee, $\mathrm{PhD}^{\mathrm{a}, \mathrm{c}}$

David B. Ross, MD
Background: Allograft heart valves used in cardiac surgery often fail at an unacceptable rate. Immune mechanisms contribute to this failure, but adequate and functional small-animal valve models to characterize this phenomenon are lacking. The objective of this study was to create native aortic valve insufficiency in recipient rats to provide for a functional abdominal aortic valve graft implant.

Methods: Lewis recipient rats underwent single-leaflet injury of their native aortic valve through a right carotid catheter injury. Animals were allowed to recover for 28 days, at which time a Lewis aortic valve graft was implanted infrarenally. Echocardiography with color flow Doppler scanning was performed before aortic injury, 1 week after aortic injury, and after abdominal implantation of a valve graft in animals with native aortic insufficiency.

Results: After aortic valve injury, all animals had moderate-to-severe aortic insufficiency with a significant increase in diastolic and systolic left ventricular dimensions. Color flow Doppler scanning revealed diastolic aortic flow reversal from the aortic valve extending to the infrarenal abdominal aorta. Aortic valve grafts were then implanted infrarenally in animals with created aortic valve insufficiency and resulted in $100 \%$ patency and preservation of leaflets at 4 weeks after implantation. Leaflet motion of the abdominal graft was visualized by means of M-mode echocardiography.

Conclusion: Compensated native aortic insufficiency results in aortic diastolic flow reversal distal to the infrarenal aorta, thus allowing normal motion of the infrarenal allograft leaflets. This functional model will provide an opportunity to investigate the role of immunologic valve injury in the failure of valve allografts. (J Thorac Cardiovasc Surg 2000;120:679-85)
$A^{1}$ llograft valves or homografts have many advantages over commercially available mechanical and bioprosthetic valves: low transvalvular gradients, low rates of thromboembolism, and resistance to infec-

From the Department of Surgery and Division of Cardiac Surgery, Division of Pediatric Cardiology, ${ }^{\mathrm{b}}$ and Department of Microbiology/Immunology, ${ }^{\mathrm{c}}$ Dalhousie University, Halifax, Nova Scotia, Canada.

Supported by The Toronto Hospital for Sick Children Research Foundation.

Received for publication April 4, 2000; revisions requested May 15, 2000; revisions received May 30, 2000; accepted for publication June 2, 2000.

Address for reprints: David B. Ross, MD, IWK Grace Health Centre, 5850/5980 University Ave, Halifax, Nova Scotia, Canada, B3J 3G9 (E-mail: dross@iwkgrace.ns.ca).

Copyright () 2000 by The American Association for Thoracic Surgery

$0022-5223 / 2000 \$ 12.00+0 \quad \mathbf{1 2 / 1 / 1 0 9 2 3 9}$

doi:10.1067/mtc.2000.109239 tion. ${ }^{1}$ They are used extensively for children who are prone to rapidly calcifying xenograft valves and for whom use of warfarin is difficult. ${ }^{1}$ However, despite these advantages, allograft valves do ultimately fail. ${ }^{2}$ This is particularly true in children in whom progressive echocardiographic failure of allograft valve implants can reach $60 \%$ within 5 years of the original operation. ${ }^{3}$

The cause of allograft valve failure in children and adults is most likely multifactorial and includes mechanical, immunologic, and other factors. Immune mechanisms have been suggested by many to contribute to this failure, but good functional valve models to study this in small inbred animals are lacking. ${ }^{4,5}$ In currently existing rat models, first described by Yankah and colleagues, ${ }^{6}$ allograft valves are implanted as an aortic interposition graft in the descending abdominal aorta. These valves are permanently open and nonfunctional and thus are prone to thrombosis against the aortic 

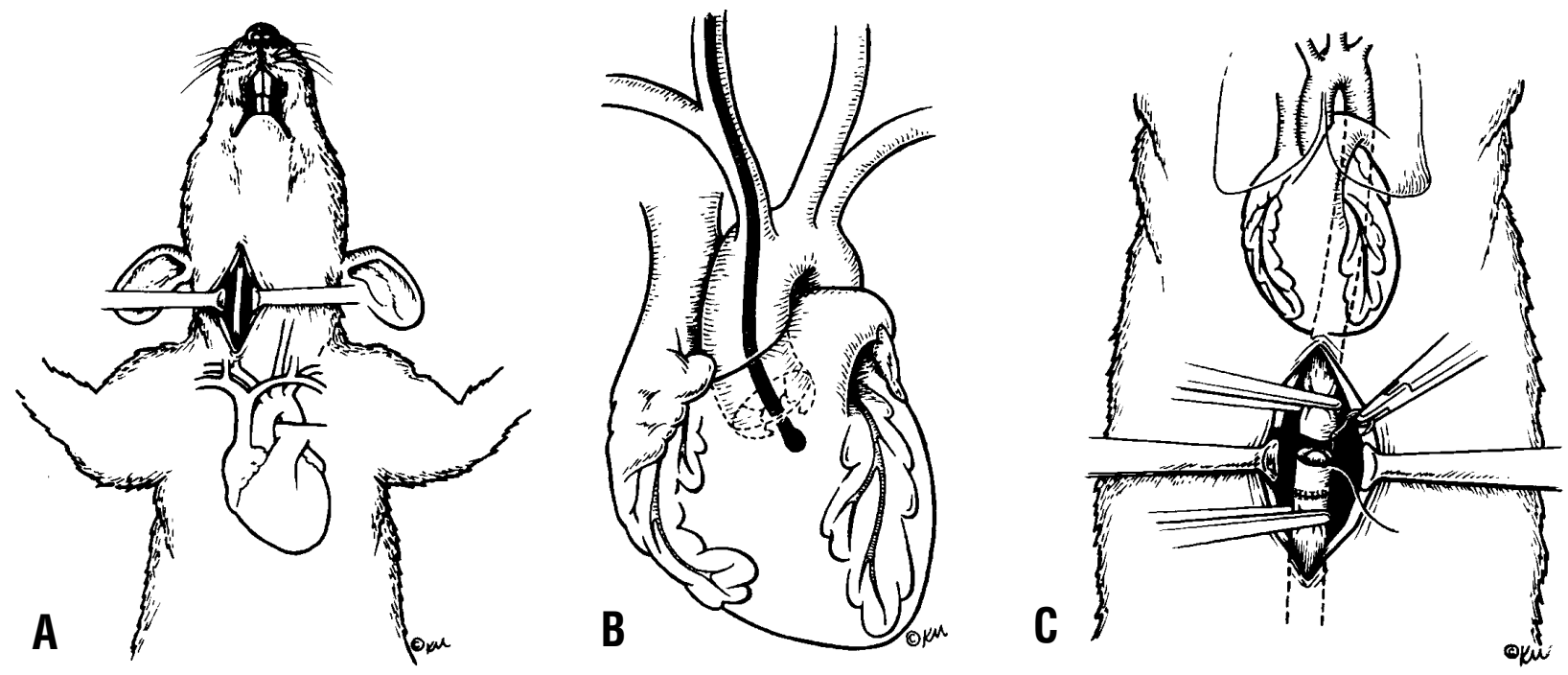

Fig 1. Artist's rendering of the stages involved in creating this new model of functional valve implantation in rats. A, The right carotid artery is exposed to allow the insertion of guide wire. $\mathbf{B}$, This guide wire disrupts the native aortic valve and creates acute AI. C, After 28 days of recovery, animals with compensated native AI undergo a second operation in which an aortic valve graft from a donor animal is implanted heterotopically in the abdominal aorta.

wall. ${ }^{7,8}$ Several attempts have been made by others to improve on this model, ${ }^{8,9}$ but these have not resolved the problem of the use of a nonfunctional heart valve for research into clinical concerns.

For a heterotopic valve implant to be functional, there must be some turbulence and reversal of blood flow in the aorta that permits leaflet closure. In the 1950s there were reports of aortic valve allografts implanted heterotopically in the descending thoracic aorta of patients with symptomatic aortic insufficiency. ${ }^{10,11}$ In these patients valve function was shown to be excellent early on and even at 7 years after implantation. ${ }^{10}$ The presence of aortic insufficiency resulted in significant diastolic flow reversal in the thoracic aorta, thus allowing leaflet motion and coaptation of the implanted valve. This technique was abandoned in humans when cardiopulmonary bypass became available, permitting orthotopic implantation. ${ }^{12}$

The objective of this study was to create native aortic valve insufficiency (AI), thus allowing flow reversal in the descending aorta of a rat. If tolerated, this would provide a recipient animal for functional heterotopic aortic valve implantation in the descending abdominal aorta. This model would represent a major leap forward in the study of aortic valve failure because it provides a functional valve to assess the interaction between immunologic and mechanical injury in allograft aortic valve failure while avoiding the need for and difficulty of orthotopic valve implantation.

\section{Methods}

Animals. Inbred male Lewis (RT1.A ${ }^{1}$ ) rats weighing 300 to $350 \mathrm{~g}$ were purchased from Harlan Sprague Dawley (Indianapolis, Ind) and housed in the Medical Sciences Animal Care Facility with food and water ad libitum for 1 week before experimentation in accordance with the guidelines of the Canadian Council of Animal Care. ${ }^{13}$

Echocardiography. Animals were anaesthetized with ketamine $\mathrm{HCl}, 100 \mathrm{mg} / \mathrm{kg}$ administered intraperitoneally (Parke Davis), and xylazine, $5 \mathrm{mg} / \mathrm{kg}$ administered intraperitoneally (Lloyd Laboratories). Heart rate was recorded continuously by means of transcutaneous echocardiography (ECG). Standard 2-dimensional, M-mode, and Doppler transthoracic and transabdominal ECG was performed with a HewlettPackard Sonos 5500 ECG machine (Hewlett-Packard Company, Andover, Mass) equipped with an S-12 MHz transducer (range, 5-12 MHz). All recordings were videotaped on super-VHS (Fuji H471S, ST120) for later analysis and image digitization. Left ventricular (LV) dimensions were measured in a standard fashion in short-axis view at the level of the papillary muscles by M-mode tracings.

Creation of $\mathbf{A I}$ in recipient Lewis rats. In anesthetized animals a midline neck incision was used to expose the right carotid artery (Fig 1,A). The distal common carotid artery was ligated with 4-0 nylon suture. An arteriotomy was then performed to allow the insertion of a $0.63-\mathrm{mm}$ guide wire with a balled tip (arrow). The wire was advanced until resistance from one cusp of the aortic valve was felt. The wire was then advanced for a few millimeters to perforate a cusp of the aortic valve and create AI (Fig 1, B). The proximal carotid artery was ligated with 4-0 nylon sutures, and animals were allowed to recover for a minimum of 28 days before aortic valve graft implantation. 


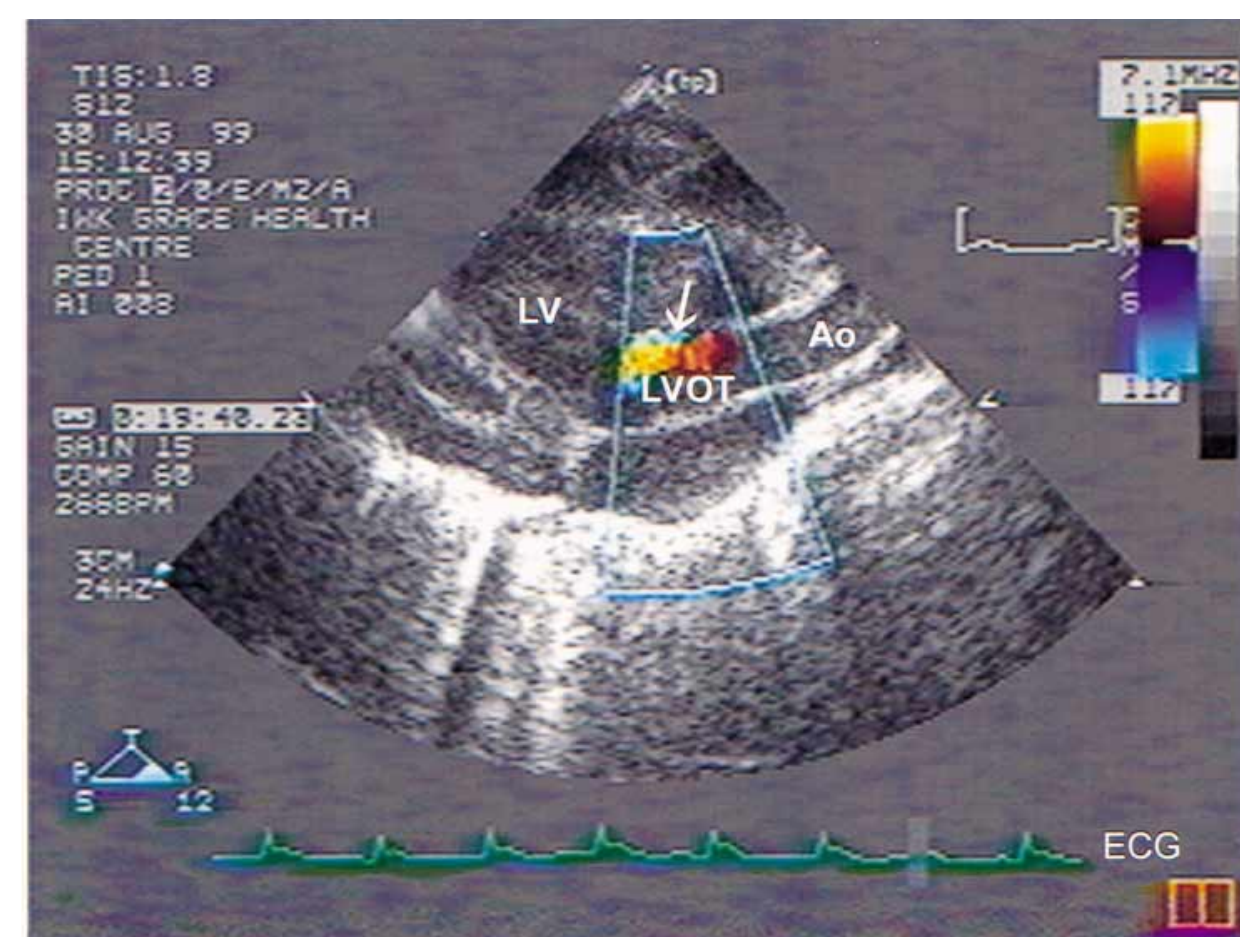

Fig 2. Color Doppler flow scanning of the left ventricular outflow tract (LVOT). Color-coded blood flow illustrates a regurgitant jet (arrow) of approximately half the width of the LVOT. Ao, Aorta; $L V$, left ventricular cavity.

Donor and recipient operations. Lewis recipient rats with AI received an aortic valve transplant, as originally described by Yankah and colleagues. ${ }^{4}$ In brief, donor aortic valve grafts were removed with a cuff of ventricular muscle and the ascending aorta. The coronary arteries were tied with a 9-0 nylon suture. For the recipient operation, the abdominal aorta was mobilized from the inferior vena cava from the level of the left renal artery almost down to the aortic bifurcation and divided between two vascular clamps. The aortic valve allograft was then interposed between the stumps of the recipient aorta with interrupted 9-0 nylon sutures.

Histology and morphometry. Four weeks after aortic valve implantation, the animals were killed. Native hearts and aortic valves were evaluated by means of a Weck (OM-1206; Pilling Weck Surgical) mounted operating microscope. Explanted abdominal grafts were immediately fixed in $10 \%$ buffered formalin solution for 24 hours. The tissues were then paraffin embedded, serially sectioned $(5 \mu \mathrm{m})$, and stained for histologic examination (hematoxylin and eosin stain).

Tissue slides from each animal were then examined by light microscopy (Nikon), and images were digitalized and captured (JVC digital camera, TK1070U). Morphometric analysis was carried out by using Adobe PhotoShop (Microsoft) and NIH Image analyzer software on a Power PC (G3, Apple Computer) to measure aortic valve leaflet surface area (in square micrometers) and cell counts per area.

Statistics. Means were obtained from several animals in each group. Data were reported as mean and SEM. An unpaired 2-tailed Student $t$ test was used to assess statistical significance.

\section{Results}

Catheter injury to the native aortic valve described in the "Methods" section is illustrated in Fig 1, $A$ and $B$. This operation was performed on 8 rats. Three rats were subsequently killed because of clinical deterioration caused by acute congestive heart failure $(62.5 \%$ survival). Transthoracic echocardiography was performed before and 1 week after injury. Catheter aortic valve injury resulted in significant acute AI in all animals (Fig 2).

Aortic insufficiency was graded as $1+$ to $4+$ on the basis of the width of the aortic insufficiency jet. The mean jet-width ratio, which is the width of the AI jet as a function of the diameter of the valve anulus, was $37 \%$ and ranged from $20 \%$ to $57 \%$. A jet-width ratio of $30 \%$ or more was considered moderate or $2+\mathrm{AI} .^{14}$ Postaortic valve injury mean systolic LV dimensions were $0.88 \pm 0.08 \mathrm{~cm}$ compared with $0.59 \pm 0.07 \mathrm{~cm}$ for preaortic valve injury $(P<.001)$. Postaortic valve injury mean diastolic LV dimensions were $0.49 \pm 0.03$ $\mathrm{cm}$ compared with $0.36 \pm 0.06 \mathrm{~cm}$ for preaortic valve injury $(P<.001)$. These echocardiographic findings are 

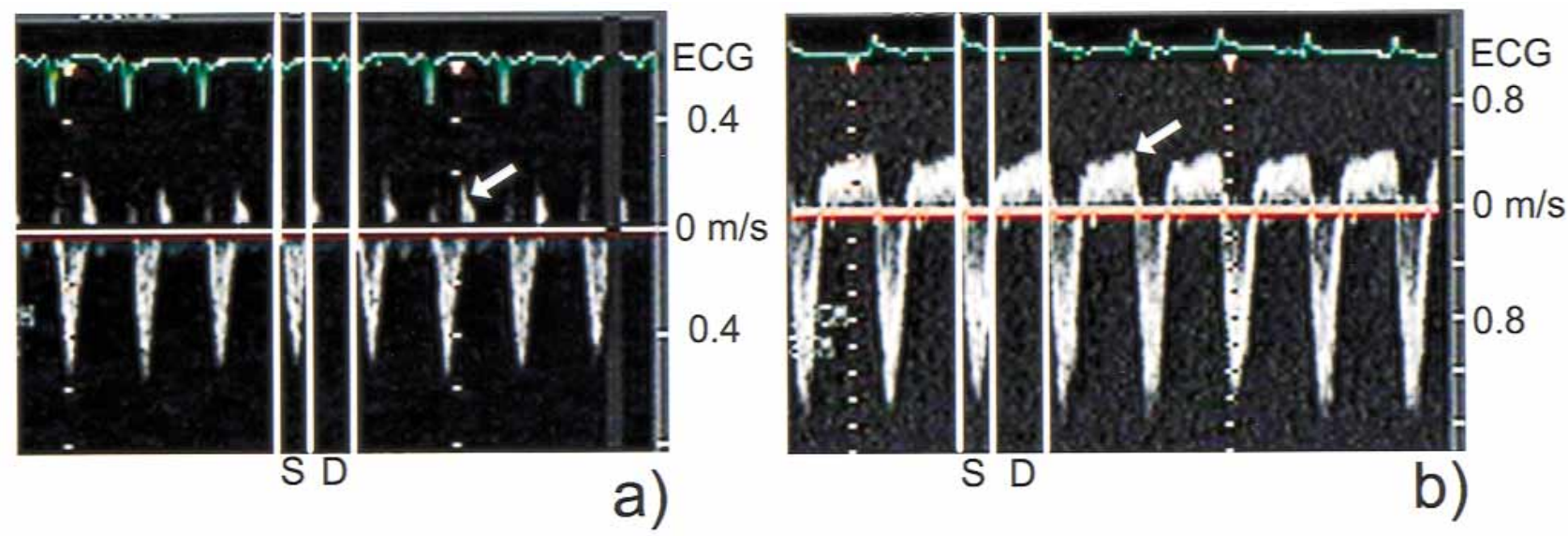

Fig 3. Doppler tracing sampled from the abdominal aorta of an animal without aortic injury (a) and with created aortic injury (b). Systole and diastole were defined on the basis of a concomitant ECG tracing. An upper deflection of the Doppler tracing from baseline represented blood flow reversal toward the heart, whereas a lower deflection from baseline represented forward blood flow toward the lower extremities. The arrow indicates significant diastolic flow reversal seen in animals after aortic valve injury (b) compared with animals without aortic valve injury (a). $D$, Diastole; $S$, systole.

Table I. Echocardiographic results before and after aortic valve injury

\begin{tabular}{lccc}
\hline & Before injury & After injury & P value \\
\hline AI & 0 & $2+$ to $3+$ & - \\
Jet width & 0 & $37 \%(20 \%-57 \%)$ & - \\
Mean diastolic dimensions $(\mathrm{cm})$ & $0.59 \pm 0.07$ & $0.88 \pm 0.08$ & $<.001$ \\
Mean systolic dimensions $(\mathrm{cm})$ & $0.36 \pm 0.06$ & $0.49 \pm 0.03$ & $<.001$ \\
Mean heart rate (beats/min) & $310 \pm 58$ & $253 \pm 16$ & .06
\end{tabular}

There were 8 animals in the preinjury group and 5 animals in the postinjury group.

summarized in Table I. Trivial mitral regurgitation was observed in most animals after injury.

Color flow Doppler scanning was used to assess the direction of blood flow during both systole and diastole in the descending abdominal aorta with reference to surface electrocardiographic tracings. Diastolic aortic flow reversal was present in all animals after aortic injury (Fig 3,b) as compared with control animals (Fig $3, a$ ) in which minimal flow reversal was only seen at the time of aortic valve closure (end-systole). Flow reversal within the descending aorta in animals with AI persisted throughout diastole and reached peak velocities of $0.4 \mathrm{~m} / \mathrm{s}$.

Animals with created AI $(n=5)$ were allowed to recover for a minimum of 28 days, after which Lewis aortic valve grafts were implanted infrarenally (Fig 1, $C)$. All animals tolerated this second surgical intervention in the setting of compensated acute AI. Echocardiography was then performed to evaluate the abdominal implant. Valve leaflets of the abdominal implant were visualized by 2-dimensional and M-mode echocardiography. The appropriate opening and closing of the leaflets was demonstrated by M-mode tracings during the cardiac cycle in an animal with created native aortic insufficiency (Fig 4).

Four weeks after abdominal valve graft implantation, animals were killed, and the abdominal implanted valve was processed for histologic evaluation. All animals showed some disruption of one leaflet or sinus of Valsalva of their injured native aortic valve with gross cardiomegaly when evaluated under the dissecting microscope (Table II). Abdominal implants were patent $(100 \%)$ and had no evidence of thrombosis. Histologically, valve leaflets appeared normal, thin, and cellular and were visualized in all cases (Fig 5). Leaflet cellular density was evaluated by morphometry and shown to be $23.3 \times 10^{3} \pm 5.4 \times 10^{3}$ cells $/ \mu \mathrm{m}^{2}$ in valves 4 weeks after implantation (Fig 5). 


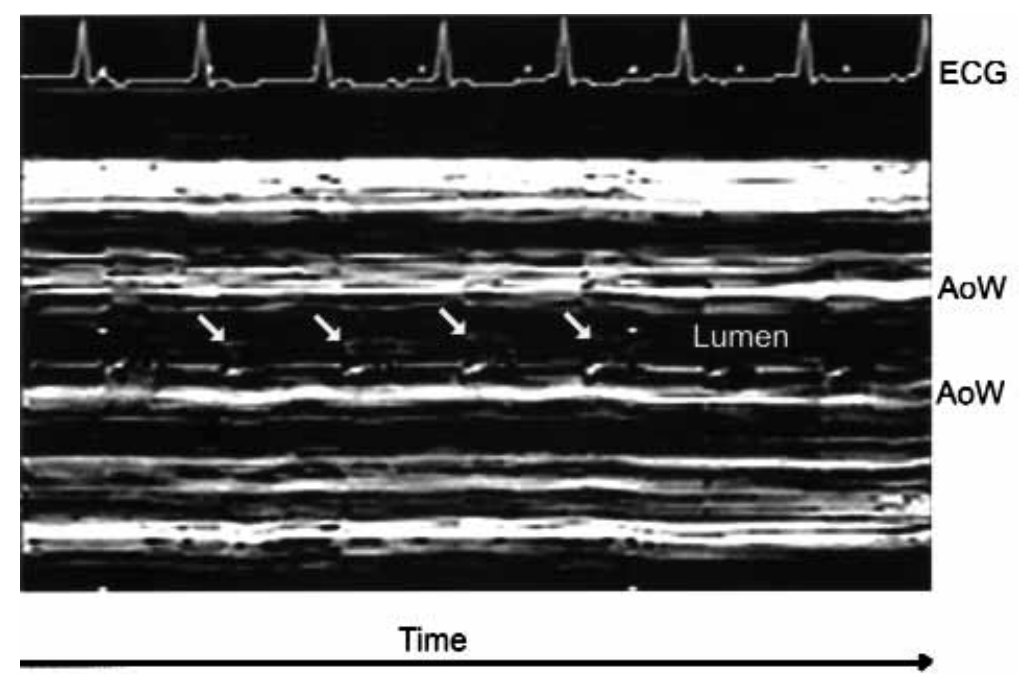

Fig 4. M-mode echocardiographic tracing sampled from the abdominal implant in an animal with AI. Arrows point to aortic leaflets of a valve implant appearing within the lumen of the aorta at regular intervals during the cardiac cycle. $A o W$, Walls of the aorta.

Table II. Pathologic evaluation of hearts from animals that have survived creation of AI and an abdominal valve implant

\begin{tabular}{llll}
\hline Animal & Harvest & Heart & Aortic valve pathology \\
\hline 1 & $4 \mathrm{wk}$ & ++ Cardiomegaly & Perforated leaflet \\
2 & $4 \mathrm{wk}$ & ++ Cardiomegaly & Sinus of Valsalva aneurysm + right atrial fistula \\
3 & $4 \mathrm{wk}$ & ++ Cardiomegaly & Perforated leaflet \\
4 & $4 \mathrm{wk}$ & ++ Cardiomegaly & Torn leaflet at commissure \\
5 & $4 \mathrm{wk}$ & ++ Cardiomegaly & Perforated leaflet \\
\hline
\end{tabular}

\section{Comment}

The availability of genetically identical inbred strains make small-animal models essential to evaluate the role of immunologic processes involved in allograft valve rejection and failure. Current rat models of infrarenal aortic valve implantation are well described and have provided important advances in our understanding of allograft failure. ${ }^{4}$ However, despite having leaflets present in the blood stream, these leaflets are not functional and therefore are not completely representative of human allograft failure. In existing smallanimal models, leaflets are prone to thrombosis against the adjacent aorta and fail unusually early compared with the clinical experience. ${ }^{7,8}$

Early work by Lam and colleagues ${ }^{15}$ in larger animals showed that experimentally it was possible to place an allograft aortic valve in the descending aorta. This was performed distal to the left subclavian artery and allowed a simpler operation without cardiopul- monary bypass support. For the transplanted valve to function normally, sufficient native AI was necessary. In 1956, Murray ${ }^{11}$ implanted a homograft aortic valve in the descending thoracic aorta of a patient with severe aortic insufficiency. Although this operation had very little effect on the regurgitation from the head vessels and upper extremities, it did prevent regurgitation from the aorta distal to the implant. This resulted in a considerable reduction on the strain placed on the left ventricle by the constant volume overload of AI. Valve implant function was shown to be excellent early and at up to 7 years of follow-up. ${ }^{10}$

Aortic valve leaflet injury models are well-established models of AI used to study the progressive development of volume overload-dependent congestive heart failure. ${ }^{16-18}$ In the rat a right carotid catheter injury has been shown to be reliable and well tolerated by animals with a single leaflet injury. ${ }^{19}$ In our animals we reliably created native AI, which was assessed by 

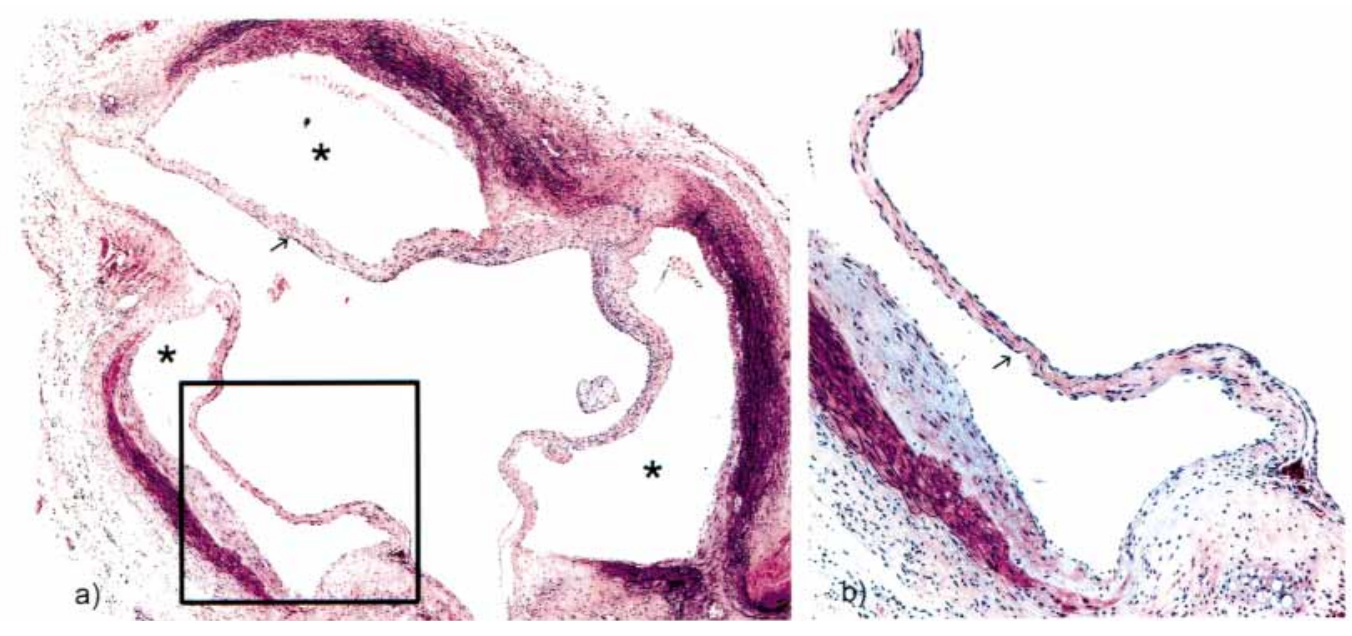

Fig 5. Representative photomicrographs taken from a harvested abdominal aortic valve graft 4 weeks after implantation. A, Low-power (40×) cross section through the valve graft showing a normal 3-cusp valve. B, High-power (200×) view of one of the leaflets demonstrating a normal cellularity, which can be quantified by nuclear counts per surface area. Arrows, Leaflets; asterisks, sinuses.

echocardiography. Previous reports have demonstrated the accuracy and reproducibility of transthoracic echocardiography in small animals. ${ }^{20}$ In our study, classic findings of AI were demonstrated and included the following: ventricular dilatation (diastolic and systolic LV dimensions); regurgitant jet from the aortic valve; and the presence of diastolic flow reversal in the descending aorta. ${ }^{14,21}$ Diastolic flow reversal was shown to be present throughout the aorta down to below the renal arteries compared with control animals in which no native AI was present. It is this flow reversal during diastole that theoretically allows leaflets to move and function during the cardiac cycle.

Lewis rats tolerated the procedure relatively well because a significant number of them $(62.5 \%)$ underwent an additional procedure where an abdominal valve graft was implanted heterotopically below the renal arteries. Valve implantation was delayed for 4 weeks to allow the animals to recover. This period of time presumably allowed some compensation of the heart to occur in response to the acute volume overload created by acute aortic valve injury and resulted in compensated AI with significant aortic diastolic flow reversal by 1 month.

Abdominal valve grafts, when explanted and examined histologically 4 weeks after implantation, all showed preservation of leaflet morphology with $100 \%$ patency. Valve leaflet morphology has largely been ignored from most previous studies that have used a rat heterotopic valve graft model. Most previous work has focused on the valve conduit rather than the leaflets. In fact, in the original model leaflets were not functional, were permanently open, and were prone to retrovalvular thrombosis. This retrovalvular thrombosis presents 3 major problems in a model of allograft valve failure. First, it renders the interpretation of the molecular and cellular events leading to valve failure in the rat model much more difficult. Second, it makes extrapolation of the data from the model to the human situation more tenuous. Third, it results in early graft failure, which could provide misleading information regarding the cause of leaflet destruction. Thus, the availability of a functional valve model is of critical importance.

We have also described a method by which leaflet cellular density can be quantified and used to evaluate leaflet preservation and integrity. This method could also be applied to evaluate infiltration by various immune effector cells by using standard immunocytochemical techniques. Cellular density appears to be particularly important in the evaluation of allograft failure because human and larger animal allograft valves have been shown to undergo loss of leaflet stromal cells by mechanisms that largely remain unclear. ${ }^{22,23}$ Taken together, this modification of a heterotopic heart valve implantation model, originally described by Yankah and colleagues, ${ }^{6}$ has the potential to increase our understanding of immune-mediated damage of allograft heart valve. 
Despite a small number of animals, this study represents the first evidence of a functional allograft aortic valve transplant in an inbred small-animal model. This improved model approaches a normal physiologically functioning valve. By using this functional model, we are hopeful that the various factors contributing to allograft valve failure can be successfully isolated, leading to successful therapeutic applications.

\section{REFERENCES}

1. Clarke DR, Campbell DN, Hayward AR, Bishop DA. Degeneration of aortic valve allografts in young recipients. J Thorac Cardiovasc Surg 1993;105:934-42.

2. Kirklin JK, Smith D, Novick W, Naftel DC, Kirklin JW, Pacifico $\mathrm{AD}$, et al. Long-term function of cryopreserved aortic homografts. J Thorac Cardiovasc Surg 1993;106:154-66.

3. Baskett RJ, Ross DB, Nanton MA, Murphy DA. Factors in the early failure of cryopreserved homograft pulmonary valves in children: Preserved immunogenicity? J Thorac Cardiovasc Surg 1996;112:1170-9.

4. Yankah AC, Wottge HU, Muller-Ruchholz W. Antigenicity and fate of cellular components of the heart valve allografts. In: Yankah AC, Hetzer R, Miller DC, Ross DN, Somerville J, Yacoub MH, editors. Cardiac valve allografts, 1962-1987. Steinkopff: Springer; 1988. p. 77-87.

5. Lupinetti FM, Christy JP, King DM, Khatib HE, Thompson SA. Immunogenicity, antigenicity, and endothelial viability of aortic valves preserved at 4 degrees Celcius in a nutrient medium. $\mathbf{J}$ Card Surg 1991;6:454-61.

6. Yankah AC, Wottge HU, Muller-Ruchholtz W. Prognostic importance of viability and a study of a second set of allograft valve: an experimental study. J Card Surg 1988;3:263-70.

7. Moustapha A, Ross DB, Bittira B, Van-Velzen D, McAlister VC, Lannon CL, et al. Aortic valve grafts in the rat: evidence for rejection. J Thorac Cardiovasc Surg 1997;114:891-902.

8. Zhou ZY, Golshani SD, Wellisz T, Rosso RF, Nimni ME, Reinisch JF. A new model for heterotopic aortic valve transplantation. Transplantation 1997;64:228-32.

9. Green Mk, Zhoa XM, Senewiratne S, McGiffin DC. A microsurgical rat model for aortic valve allografts. Transplant Proc 1992;24:2286.

10. Kerwin AJ, Lenkei SC, Wilson DR. Aortic valve homograft in the treatment of aortic insufficiency: report of nine cases, with one followed for six years. N Engl J Med 1962;266:852-7.

11. Murray G. Homologous aortic-valve-segment transplants as surgical treatment for aortic and mitral insufficiency. Angiology 1956;7:446-71.

12. Ross DN. Homograft replacement of the aortic valve. Lancet 1962;2:487-8.

13. Olfert ED, Cross BM, McWillims AA, editors. Guide to the care and use of experimental animals. Vol 1, 2nd ed. Canadian Council of Animal Care; 1993.

14. Tani LY, Minich LL, Day RW, Orsmond GS, Shaddy RE. Doppler evaluation of aortic regurgitation in children. Am J Cardiol 1997;80:927-31.

15. Lam CR, Aram HH, Munnell ER. Experimental study of aortic valve homografts. Surg Gynecol Obstet 1952;94:129-35.

16. Kimura M, Umemura K, Ohashi K, Nakashima M. Effect of ecadotril, a neutral endopeptidase inhibitor, on myocardial hypertrophy in the rat aortic insufficiency model. Can J Cardiol 1998;14:63-8.

17. Katz AM. Cell death in the failing heart: role of an unnatural growth response to overload. Clin Cardiol 1995;18(Suppl 4):IV36-44.

18. Morita H, Tanaka I, Oda T, Ishiyama A, Yamazaki T, Uematsu T, et al. Atrial natriuretic peptide messenger RNA and peptide in rats with aortic valve insufficiency. Peptides 1990;11:843-7.

19. Uematsu T, Yamazaki T, Matsuno H, Hayashi Y, Nakashima M. A simple method for producing graded aortic insufficiencies in rats and subsequent development of cardiac hypertrophy. J Pharmacol Methods 1989;22:249-57.

20. Manning WJ, Wei JY, Katz SE, Litwin SE, Douglas PS. In-vivo assessment of LV mass in mice using high-frequency cardiac ultrasound: necropsy validation. Am J Physiol 1994;226: H1672-5.

21. Sutton DC, Kluger R, Ahmed SU, Reimold SC, Mark JB. Flow reversal in the descending aorta: a guide to intraoperative assessment of aortic regurgitation with transesophageal echocardiography. J Thorac Cardiovasc Surg 1994;108:576-82.

22. Mitchell RN, Jonas RA, Schoen FJ. Pathology of explanted cryopreserved allograft heart valves: comparison with aortic valves from orthotopic heart transplants. J Thorac Cardiovasc Surg 1998;115:118-27.

23. Hilbert SL, Luna RE, Zhang J, Wang Y, Hopkins RA, Yu ZX, et al. Allograft heart valves: the role of apoptosis-mediated cell loss. J Thorac Cardiovasc Surg 1998;117:454-62. 